\title{
Review \\ Genetic Biomarkers of Metabolic Detoxification for Personalized Lifestyle Medicine
}

\author{
Lucia Aronica ${ }^{1,2, *}$, Jose M. Ordovas ${ }^{3,4,5}$, Andrey Volkov ${ }^{6}$, Joseph J. Lamb ${ }^{7}{ }^{10}$, Peter Michael Stone ${ }^{7,8,9,10}$, \\ Deanna Minich ${ }^{8,11}{ }^{10}$, Michelle Leary ${ }^{12}$, Monique Class ${ }^{8,13}$, Dina Metti ${ }^{7}{ }^{\circledR}$, Ilona A. Larson ${ }^{1}$, Nikhat Contractor ${ }^{14}$, \\ Brent Eck ${ }^{1}$ and Jeffrey S. Bland ${ }^{15}$
}

check for

updates

Citation: Aronica, L.; Ordovas, J.M.;

Volkov, A.; Lamb, J.J.; Stone, P.M.;

Minich, D.; Leary, M.; Class, M.;

Metti, D.; Larson, I.A.; et al. Genetic

Biomarkers of Metabolic

Detoxification for Personalized

Lifestyle Medicine. Nutrients 2022, 14, 768. https://doi.org/10.3390/

nu14040768

Received: 18 January 2022

Accepted: 8 February 2022

Published: 11 February 2022

Publisher's Note: MDPI stays neutral with regard to jurisdictional claims in published maps and institutional affiliations.

Copyright: (C) 2022 by the authors. Licensee MDPI, Basel, Switzerland This article is an open access article distributed under the terms and conditions of the Creative Commons Attribution (CC BY) license (https:// creativecommons.org/licenses/by/ $4.0 /)$.
1 Department of Nutrition Science, Metagenics, Inc., Aliso Viejo, CA 92656, USA; ilonalarson@metagenics.com (I.A.L.); brenteck@metagenics.com (B.E.)

2 Stanford Prevention Research Center, Department of Medicine, Stanford University, California, CA 94305, USA

3 Nutrition and Genomics Laboratory, Jean Mayer USDA Human Nutrition Center on Aging, Tufts University, Boston, MA 02111, USA; jose.ordovas@tufts.edu

4 Nutritional Genomics and Epigenomics Group, IMDEA-Food, 28049 Madrid, Spain

5 University Camilo José Cela, Villafranca del Castillo, 28692 Madrid, Spain

6 Bennet Data Sciences, San Diego, CA 92107, USA; andrey@bennettdatascience.com

7 Personalized Lifestyle Medicine Center, Gig Harbor, WA 98332, USA; josephlamb@plmc.com (J.J.L.); mstone@ashlandmd.com (P.M.S.); dinametti@plmc.com (D.M.)

8 Institute for Functional Medicine Federal Way, Washington, DC 98003, USA; deannaminich@hotmail.com (D.M.); monique@thecffm.com (M.C.)

9 Ashland Comprehensive Family Medicine-Stone Medical, Ashland, OR 97520, USA

10 Office of Personalized Health and Well-Being, Medical College of Georgia, AU/UGA Medical Partnership, Athens, GA 30606, USA

11 Human Nutrition and Functional Medicine, University of Western States, Portland, OR 97213, USA

12 Vida Integrated Health, Seattle, WA 98112, USA; mleary@thinkvida.com

13 The Center for Functional Medicine, Stamford, CT 06905, USA

14 Nutrilite Health Institute, Buena Park, CA 90621, USA; nikhat.contractor@amway.com

15 Personalized Lifestyle Medicine Institute, Bainbridge Island, WA 98110, USA; jeffbland@plminstitute.org

* Correspondence: lucia.aronica@metagenics.com

\begin{abstract}
Metabolic detoxification (detox)—or biotransformation—is a physiological function that removes toxic substances from our body. Genetic variability and dietary factors may affect the function of detox enzymes, thus impacting the body's sensitivity to toxic substances of endogenous and exogenous origin. From a genetic perspective, most of the current knowledge relies on observational studies in humans or experimental models in vivo and in vitro, with very limited proof of causality and clinical value. This review provides health practitioners with a list of single nucleotide polymorphisms (SNPs) located within genes involved in Phase I and Phase II detoxification reactions, for which evidence of clinical utility does exist. We have selected these SNPs based on their association with interindividual variability of detox metabolism in response to certain nutrients in the context of human clinical trials. In order to facilitate clinical interpretation and usage of these SNPs, we provide, for each of them, a strength of evidence score based on recent guidelines for genotype-based dietary advice. We also present the association of these SNPs with functional biomarkers of detox metabolism in a pragmatic clinical trial, the LIFEHOUSE study.
\end{abstract}

Keywords: detoxification; biotransformation; biomarkers; nutrigenomics; single nucleotide polymorphisms; personalized lifestyle medicine; pragmatic clinical trials; functional medicine; environmental health; LIFEHOUSE study 


\section{Introduction}

Every day, we are exposed to hundreds of toxic substances of endogenous and exogenous origin, including radical oxygen species produced during cellular respiration and foreign compounds known as xenobiotics such as environmental toxicants, food additives, and drugs. Detoxification(detox) and biotransformation are physiological functions that removes these substances from our body in three separate phases (I to III). Defective detox due to genetic factors, environmental overload, and nutrient deficiencies can result in various chronic diseases, including cancer, asthma, obesity, cardiovascular disease, diabetes [1], and neurodegenerative conditions such as Alzheimer's disease [2].

Genetic variants and dietary factors may affect the function of Phase I and Phase II detox, thus impacting the body's sensitivity and response to toxic exposures. In Phase I, functionalization enzymes break down xenobiotics in the liver, producing highly reactive free radical molecules as a byproduct. These activated xenobiotics can damage cell structure and function unless further processed in Phase II or neutralized by endogenous or exogenous antioxidants. In Phase II, conjugation enzymes join activated xenobiotics with large molecules to produce water-soluble substances that are finally excreted from the body in Phase III, the elimination phase, mainly via urine or stools. Several common single nucleotide polymorphisms (SNPs, minor allele frequency $\geq 1 \%$ ) have been reported to affect the function of Phase I and Phase II detox enzymes and the manner dietary factors modulate these enzymes. However, the scientific validity and clinical utility of these SNPs are still unclear as most of the current knowledge relies on observational studies in humans or experimental models in vivo and in vitro, with very limited proof of causality and clinical value.

This study provides health practitioners with a review and analysis of state-of-the-art research on genetic variants that could be used for personalized metabolic detoxification programs. In the first section of the paper, we provide a list of SNPs located within genes involved in Phase I and Phase II detoxification reactions, for which some evidence of clinical utility exists. In the second section of the paper, we present the association of these SNPs with functional biomarkers of detox metabolism in the Lifestyle Intervention and Functional Evaluation-Health Outcome Survey (LIFEHOUSE), a real-world pragmatic clinical trial (PCT).

\section{Clinically Tested Genetic Variants within Genes Involved in Phase I/Phase II Detox Reactions}

Table 1 provides a list of clinically tested single nucleotide polymorphisms (SNPs) located within genes involved in Phase I and Phase II detoxification reactions. A list of foods and nutrients interacting with those SNPs to modulate detox metabolism is presented in Table 2. We have selected these SNPs based on their association with inter-individual variability of detox metabolism in response to certain nutrients in the context of human clinical trials. For each of these SNPs, we provide a strength of evidence score based on recent guidelines for the interpretation and classification of nutrigenetic variants [3]. All SNP alleles are reported on the forward strand as in the dbSNP database and some direct-to-consumer genetic reports (e.g., 23andMe). 
Table 1. Common genetic variants within genes involved in Phase I/Phase II detox reactions associated with variability of response to foods or nutrients that modulate detox metabolism.

\begin{tabular}{|c|c|c|}
\hline Phase I Detox Enzyme & & \\
\hline \multicolumn{3}{|l|}{ CYP1A2 } \\
\hline Effect allele & Allele frequency & Effects on enzymatic function \\
\hline $\begin{array}{c}\text { rs762551-C } \\
\text { Strength of evidence: } \\
\text { Convincing }(\mathrm{A}) \text {. }\end{array}$ & $\begin{array}{l}\Rightarrow \quad \text { C: } 37 \% \\
\Rightarrow \quad \text { A: } 63 \%\end{array}$ & $\begin{array}{l}\text { C-allele carriers produce an enzyme variant with } 62-70 \% \\
\text { lower activity and are less inducible by xenobiotics. Low } \\
\text { CYP1A activity can result in decreased clearance of toxins, a } \\
\text { lower 2/16-alpha hydroxyestrone ratio, and a higher risk of } \\
\text { certain cancers. Consequently, lower production of reactive } \\
\text { detoxification intermediates may reduce oxidative stress. }\end{array}$ \\
\hline \multicolumn{3}{|l|}{ CYP1B1 } \\
\hline Effect allele & Allele frequency & Effects on enzymatic function \\
\hline $\begin{array}{l}\text { rs1056836-C } \\
\text { Strength of evidence: } \\
\text { Possible }(C) .\end{array}$ & $\begin{array}{l}\Rightarrow \text { G: } 61 \% \\
\Rightarrow \quad \text { C: } 39 \%\end{array}$ & $\begin{array}{c}\text { Individuals with the CC genotype tend to have higher } \\
\text { enzymatic activity than G-allele carriers, which may result } \\
\text { in greater activation of toxicants, greater production of } \\
\text { 4-hydroxy estrogens, and greater oxidative damage. The } \\
\text { effects of this SNP are affected by age, ethnicity, and } \\
\text { menopausal status. }\end{array}$ \\
\hline
\end{tabular}

Phase II detox enzymes

\begin{tabular}{|c|c|c|}
\hline Effect allele & Allele frequency & Effects on enzymatic function \\
\hline $\begin{array}{l}\text { GSTM1 deletion } \\
\text { GSTT1 deletion } \\
\text { Strength of evidence: } \\
\text { Probable (B). }\end{array}$ & $\begin{array}{r}\Rightarrow-: 33-73 \% * \\
+:: 27-67 \% \\
\Rightarrow-: 33-73 \% \\
++: 27-67 \%\end{array}$ & $\begin{array}{l}\text { Individuals carrying GSTM1 or GSTT1 double deletions (-/- } \\
\text { genotype) may have a decreased ability to detoxify } \\
\text { environmental toxicants, carcinogens, and products of } \\
\text { oxidative stress. Gene deletions are more frequent among } \\
\text { Caucasian and Asian populations and less frequent in } \\
\text { African populations. Different segmental deletions have } \\
\text { different frequencies in the population and between } \\
\text { different ethnicities. }\end{array}$ \\
\hline
\end{tabular}

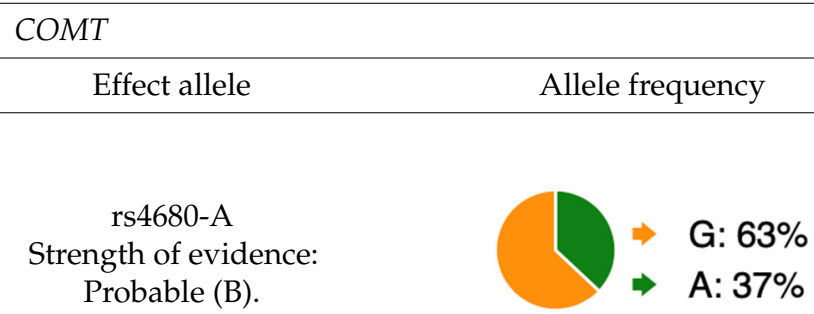

\section{Effects on enzymatic function}

The A allele (Met) produces an enzyme with $40 \%$ lower activity than that encoded by the $\mathrm{G}$ allele (Val). A-allele carriers may have a decreased ability to degrade neurotransmitters, estrogen, and various xenobiotics. This may result in increased sensitivity to environmental toxicants, a higher risk of developing neuropsychiatric disorders, and impaired estrogen metabolism.

UGT1A1

Effect allele

rs3064744-TA

Strength of evidence:

Possible (C).
Allele frequency

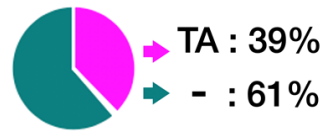

\section{Effects on enzymatic function}

Individuals carrying two insertion alleles (TA/TA genotype) may have a lower enzymatic activity than those carrying at most one copy of the deletion allele (-). This may result in increased toxicity in response to certain drugs

(acetaminophen) and to a benign cardio-protective condition known as Gilbert syndrome, characterized by increased serum levels of total and unconjugated bilirubin.

Abbreviations: SNP identification numbers (noted as "rs...") are the unique SNP identifiers from the NCBI dbSNP database. CYP1A2: Cytochrome P-450 1A2; CYP1B1: Cytochrome P-450 1B1; GSTM1: Glutathione S-transferase mu 1; GSTT1: Glutathione S-transferase theta 1; COMT: Catechol-O-methyltransferase; UGT1A1: UDP-glucuronosyltransferase A-1. 
Table 2. Foods and nutrients that modulate the activity of Phase I/Phase II enzymes and their interaction with genotype.

\begin{tabular}{|c|c|c|}
\hline Food/Nutrient & Gene & Effects on Enzymatic Function \\
\hline Caffeine & CYP1A2 & $\begin{array}{l}\text { Caffeine is an inducer and substrate of } C Y P 1 A 2 \text {. rs762551-C allele carriers are "slow" caffeine } \\
\text { metabolizers, and they should limit coffee consumption to }<1 \text { cup/day or caffeine from other } \\
\text { drinks to }<100 \mathrm{mg} \text { /day to avoid being at higher risks of hypertension and myocardial } \\
\text { infarction. In contrast, those with the AA genotype are "rapid" caffeine metabolizers and may } \\
\text { benefit from consuming } 1-4 \text { cups of coffee/day due to increased consumption of } \\
\text { phytonutrients presumed to be protective against heart disease. }\end{array}$ \\
\hline \multirow{3}{*}{$\begin{array}{l}\text { Cruciferous } \\
\text { vegetables } \\
\text { (broccoli, } \\
\text { Brussels sprouts, } \\
\text { cauliflower, } \\
\text { watercress, and } \\
\text { cabbage) }\end{array}$} & CYP1A2 & $\begin{array}{c}\text { May increase CYP1A2 activity, but it is unclear whether the magnitude of this effect may } \\
\text { depend on CYP1A genotype. }\end{array}$ \\
\hline & $\begin{array}{l}\text { GSTM1, } \\
\text { GSTT1 }\end{array}$ & $\begin{array}{l}\text { Individuals carrying gene deletions in GSTM1 or GSTT1, especially those carrying deletions in } \\
\text { both genes, may have a more rapid excretion of bioactive nutrients found in cruciferous } \\
\text { vegetables such as isothiocyanates and sulforaphane. Consequently, they may need to consume } \\
\text { greater amounts of cruciferous vegetables than those who carry at least one copy of either } \\
\text { GSTM1 or GSTT1. On the other side, double-deletion carriers tend to experience a greater } \\
\text { increase in GST activity and GST-mediated detoxification upon consumption of cruciferous } \\
\text { vegetables or cruciferous-based supplements such as 2-phenethyl isothiocyanate (PEITC). The } \\
\text { GST-inducing effects of cruciferous vegetables are more pronounced in females than in males. }\end{array}$ \\
\hline & UGT1A1 & $\begin{array}{c}\text { May decrease serum bilirubin levels in rs3064744-TA allele carriers with greater effects } \\
\text { observed for TA/TA homozygous. }\end{array}$ \\
\hline
\end{tabular}

May decrease CYP1A2 activity, but it is unclear whether the magnitude of this effect may

Apiaceous
vegetables

GSTM1, May exert inhibitory effects on GSTM1 in men, not women, who carry at least one copy of the

(carrots, celery,

dill, parsley,

parsnips, etc.)

GSTT1 GSTM1 gene.

UGTA1 May decrease serum bilirubin levels in rs3064744-TA allele carriers with greater effects observed for TA/TA homozygous.

\begin{tabular}{|c|c|c|}
\hline \multirow[b]{2}{*}{$\begin{array}{l}\text { Quercetin and } \\
\text { antioxidant rich } \\
\text { foods (citrus } \\
\text { fruits, apples, } \\
\text { onions, red wine, } \\
\text { olive oil, dark } \\
\text { berries, etc.) }\end{array}$} & CYP1B1 & $\begin{array}{l}\text { Quercetin may reduce oxidative stress to a greater extent in rs1056836-G allele carriers than in } \\
\text { those with the CC genotype. These findings were made with quercetin from fruit juices at doses } \\
\text { significantly lower }(\sim 100 \mathrm{mg}) \text { than those typically used for supplementation (500-1000 mg). }\end{array}$ \\
\hline & $\begin{array}{l}\text { GSTM1, } \\
\text { GSTT1 }\end{array}$ & $\begin{array}{l}\text { Quercetin and other antioxidants from blueberry, apples, and purple grapes may reduce } \\
\text { oxidative stress to a greater extent in GST double deletion carriers than GST-positive } \\
\text { individuals. Smokers who carry GST deletions may especially benefit from supplementation } \\
\text { with antioxidants because carcinogens in cigarette smoke can overload their detox capacity and } \\
\text { induce a higher production of ROS byproducts. However, quercetin and other antioxidants } \\
\text { seem to improve certain oxidative stress markers such as glutathione levels and vitamin C to a } \\
\text { greater extent in those with at least one copy of GSTM-1 or GSTT-1. }\end{array}$ \\
\hline Tea catechins & COMT & $\begin{array}{l}\text { Individuals with the rs } 4680 \text { AA genotype, who have slow COMT activity, may be slow catechin } \\
\text { metabolizers and retain more catechins in the blood than those with the GG genotype. As a } \\
\text { result, they may benefit from a lower intake of tea catechins. In contrast, those with the GG } \\
\text { genotype, who have higher COMT activity, may be more sensitive to the short-term effects of } \\
\text { tea catechins, such as an increase in insulin secretion and blood pressure (BP). }\end{array}$ \\
\hline $\begin{array}{l}\text { Olive oil, red } \\
\text { wine }\end{array}$ & COMT & $\begin{array}{l}\text { Individuals with the rs4680 GG genotype, who have higher COMT activity, may experience the } \\
\text { health benefits of olive oil and red wine at lower intakes than those with the AA genotype. This } \\
\text { is due to a greater ability to convert hydroxytyrosol, a phenolic compound in virgin olive oil } \\
\text { and red wine, into its cardioprotective metabolite homovanillyl alcohol (HVAL). }\end{array}$ \\
\hline
\end{tabular}

Citrus fruit

UGT1A1

May help lower serum bilirubin in women with the rs3064744 TA/TA genotype. These effects may be noticeable in all TA allele carriers.

Abbreviations: SNP identification numbers (noted as "rs...") are the unique SNP identifiers from the NCBI dbSNP database. CYP1A2: Cytochrome P-450 1A2; CYP1B1: Cytochrome P-450 1B1; GST: Glutathione Stransferase; GSTM1: Glutathione S-transferase mu 1; GSTT1: Glutathione S-transferase theta 1; COMT: CatecholO-methyltransferase; UGT1A1: UDP-glucuronosyltransferase A-1; ROS: Radical Oxygen Species. 


\subsection{Phase I Detox Enzymes}

The cytochrome P450 (CYP450) superfamily of enzymes constitutes oxidase enzymes that use oxygen to metabolize toxic compounds of exogenous or endogenous origin (e.g., pharmaceuticals, environmental toxicants, and some metabolites of steroid hormones) in Phase I detoxification reactions and synthesize various molecules within cells such as cholesterol, steroids, and bile acids. Phase I enzymes have the potential to induce oxidative damage due to the production of reactive electrophilic species, which require Phase II detoxification (conjugation) in order to be safely cleared from the body.

\subsubsection{Cytochrome P-450 1A2}

Cytochrome P-450 1A2 (CYP1A2) is a Phase I detoxification enzyme. CYP1A2 activates polycyclic aromatic hydrocarbons (PAHs) from cigarette smoke, car exhaust, and charbroiled foods to carcinogenic intermediates [4]. Various dietary factors and xenobiotics can induce the expression of the CYP1A2 gene, including caffeine, cruciferous vegetables, paracetamol, aflatoxin B1, and cigarette smoke [4,5]. The rs762551 variant is an intron variant that has been reported to affect the inducibility of CYP1A2 expression by xenobiotics such as caffeine or cigarette smoking, likely through effects on gene transcription or splicing [6-8]. The rs762551(C) allele has been reported to be a "slow-metabolizing allele," whereas the rs762551(A) allele is "a fast-metabolizing allele." C-allele carriers produce an enzyme variant with a 62-70\% lower activity and are less inducible by xenobiotics than the enzyme variant produced by those with the AA genotype [9-11]. Low CYP1A activity can result in decreased detoxification, lower 2/16-alpha hydroxyestrone ratio, and a higher risk of certain cancers $[12,13]$. On the other hand, increased activity of CYP1A without an increase in Phase II clearance may result in the accumulation of intermediates that are more reactive than the original toxins, resulting in increased oxidative damage and cancer risk $[14,15]$.

Caffeine is an inducer and substrate of CYP1A2. C-allele carriers are "slow" caffeine metabolizers compared to those with the AA genotype, as evidenced by lower levels of caffeine metabolites such as 1,7-dimethylxanthine and 1,7-dimethyluric after a dose of caffeine [9]. A prospective study of individuals screened for stage 1 hypertension [16] and two case-control studies in myocardial infarction (MI) patients $[17,18]$ suggest that C-allele carriers should limit coffee consumption to less than 1 cup/day or caffeine from other drinks to less than $100 \mathrm{mg}$ / day to avoid being at higher risk of hypertension and myocardial infarction. In contrast, those with the AA genotype are "rapid" caffeine metabolizers and may benefit from consuming 1-4 cups of coffee/day due to increased consumption of phytonutrients presumed to be protective against heart disease.

Cruciferous vegetables (broccoli, Brussels sprouts, cauliflower, watercress, and cabbage) may increase CYP1A2 activity. In contrast, apiaceous vegetables (carrots, celery, dill, parsley, and parsnips) may decrease it, but these effects do not seem to depend on the CYP1A2 genotype. In a randomized, crossover feeding trial, the consumption of cruciferous vegetables for two weeks increased CYP1A2 activity in a dose-dependent manner in all rs762551 genotypes compared with a low-phytochemical diet, with men experiencing greater dose-response than women [19]. In the same study, the consumption of apiaceous vegetables and cruciferous vegetables for two weeks decreased CYP1A2 activity compared with a diet containing cruciferous vegetables alone [19].

\subsubsection{Cytochrome P450 1B1}

Cytochrome P450 1B1 (CYP1B1) is a Phase I detoxification enzyme that localizes to the endoplasmic reticulum (ER) and metabolizes procarcinogens and estrogens. For example, it converts 17 beta-estradiol to 4-hydroxyestradiol, a mutagenic metabolite that has been implicated in breast and endometrial carcinogenesis.

The rs1056836(G) allele of the CYP1B1 gene changes an amino acid in the protein sequence from valine to leucine, which has been associated with lower enzyme activity [20]. This may result in reduced activation of toxicants, reduced production of 4- 
hydroxyestrogens, and reduced oxidative damage. As a result, individuals with GG and CG genotypes may have greater protections against exposure to pro-carcinogens than those with the CC genotype [21]. In contrast, individuals with CC genotypes tend to have higher enzymatic activity and produce 2-4 times more 4-hydroxyestrogen than those with the GG genotype [22]. They might, hence, be at higher risk for estrogen-associated cancers. However, the effects of this SNP on cancer risk are not clear and may depend on age, ethnicity, and menopausal status [23,24].

The consumption of fruit juice rich in the flavonoid quercetin, a modulator of CYP450 activity [25], has been reported to reduce oxidative stress to a greater extent in rs1056836(G)allele carriers than in those with the CC genotype. In a clinical trial in 168 healthy volunteers, the consumption of a blueberry/apple juice providing $97 \mathrm{mg}$ quercetin and $16 \mathrm{mg}$ of ascorbic acid a day for 4-weeks reduced ex vivo $\mathrm{H}_{2} \mathrm{O}_{2}$-provoked oxidative DNA damage to a greater extent in lymphocytes from G-allele carriers than in those with the CC genotype [20].

\subsection{Phase II Detox Enzymes}

\subsubsection{Glutathione S-Transferases Mu 1 (GSTM1) and Theta 1 (GSTT1)}

Glutathione S-transferases mu 1 (GSTM1) and theta 1 (GSTT1) are Phase II enzymes involved in detoxifying harmful electrophilic compounds of endogenous or exogenous origin, including environmental toxicants, therapeutic drugs, and products of oxidative stress such as lipid peroxidation products. This is accomplished by the conjugation of glutathione to highly reactive Phase I intermediate metabolites to produce water-soluble substances that can be removed from the body. Radical oxygen species and a variety of foods, phytonutrients, and xenobiotics can induce the production of these enzymes, possibly by the upregulation of the Nrf2 signaling pathway.

Many people carry genetic deletions in one or both copies of GSTT1 and GSTM1 genes. These deletions have different frequencies in different ethnic groups, being present in more than $70 \%$ of Caucasians and Asians but less than 25\% of Africans [26,27]. Deletions of both copies of the GSTM1 or GSTT1 genes are often referred to as double deletions. Individuals carrying GSTM1 or GSTT1 double deletions may have a decreased ability to detoxify environmental toxicants, carcinogens, and products of oxidative stress. This results in an increased risk of developing cancers [28] but also in increased sensitivity to chemotherapy and better treatment outcomes [29-31]. The effect of GST genotype on chemotherapy sensitivity highly depends on the type of drug used (e.g., alkylating agents or kinase inhibitors).

GSTM1 and GSTT1 deletions can modulate the effects of certain nutrients on GST activity and the required intake of those nutrients for adequate support of detox reactions. Individuals carrying gene deletions in GSTM1 or GSTT1, especially those carrying deletions in both genes, may have a more rapid excretion of bioactive nutrients found in cruciferous vegetables such as isothiocyanates and sulforaphane [32,33]. In particular, individuals with GSTM1 null/null genotype (double deletions) were found to excrete $\sim 30 \%$ more urinary sulforaphane and other isothiocyanates than GSTM1-positive individuals in both a randomized crossover trial in 16 healthy adults [32] and a feeding study in 114 healthy adults [33]. Consequently, GST double deletion carriers may need to consume more crucifers than those who carry at least one copy of GSTM1 or GSTT1 to experience health benefits. This may explain why observational studies report greater cancer-protecting benefits for double deletion carriers vs. GST-positive individuals only in European and Asian populations [34-36] but not in the United States [37-40], probably due to lower intakes of cruciferous vegetables in the US compared to Europe and Asia.

Clinical studies report that cruciferous vegetables increase the activity of GST enzymes to a greater extent in those who carry a GSTM1 or GSTT1 deletion compared to GST-positive individuals [22,41]. However, others did not confirm this association [42-44]. In line with these findings, GST double deletion carriers show a greater increase in GST-mediated detoxification than GST-positive individuals after consuming cruciferous-based supplements. In a randomized crossover trial in 82 smokers, oral 2-phenethyl isothiocyanate (PEITC), a 
compound from the watercress, which is a cruciferous plant, increased the urinary excretion metabolites of carcinogens found in cigarette smoke (i.e., mercapturic acids of benzene and acrolein) [45]. Smokers with GSTM1 null/null genotype experienced higher increases in mercapturic acids of benzene (43\%) compared to the placebo controls than the individuals with one or two gene copies (11\%). If they also had a double deletion of the GSTT1 gene, they experienced even greater increases in urinary mercapturic acids of benzene (95.4\%) after PEITC supplementation. In contrast, those who had at least one copy of both GSTM1 and GSTT1 did not experience any detox-enhancing effect from PEITC supplementation.

However, gender and lifestyle factors such as smoking can modify the interaction between GST genotype and dietary factors on GST activity. Cruciferous vegetables may increase GST activity in those who carry deletions of both copies of GSTM1, with effects more pronounced in females than in males [22,41,45]. In contrast, apiaceous vegetables seem to inhibit GSTM1 specifically in men, not women, who carry at least one copy of the GSTM1 gene. These effects were observed in a clinical study of adult non-smokers after consuming either cruciferous vegetables or apiaceous vegetables for a period of 6-days [22].

Antioxidants-rich food may decrease oxidative stress to a greater extent in GST double deletion carriers than GST-positive individuals. In a clinical trial referenced above, individuals with two copies of the GSTT1 gene benefited more from the consumption of a blueberry/apple juice providing $97 \mathrm{mg}$ quercetin and $16 \mathrm{mg}$ ascorbic acid a day with respect to reducing risks of oxidative DNA damage compared with individuals with one copy or with double gene deletions [20].

Smokers who carry GST deletions may particularly benefit from supplementation with antioxidants because carcinogens in cigarette smoke can overload their detox capacity and induce a higher production of ROS byproducts. However, antioxidants seem to improve certain oxidative stress markers such as glutathione levels and vitamin $C$ to a greater extent in those with at least one copy of GSTM1 or GSTT1. In a study in 95 adult Korean male smokers, all participants experienced significant reductions in DNA damage upon supplementation with purple grape juice. The antioxidant impact of the grape juice differed based on the genotype. Only individuals with one or two copies of the GSTT1 gene (GSTT1 present/present or present/null) experienced significant increases in blood vitamin C concentrations. In addition, only individuals with double GSTM1 deletions (null/null genotype) experienced significant increases in plasma vitamin E concentrations. In contrast, glutathione levels were increased in those with one or two copies of the GSTM1 gene (GSTM1 present/present or present/null) [46].

\subsubsection{Catechol-O-Methyltransferase (COMT)}

Catechol-O-methyltransferase (COMT) is involved in phase II (conjugative) metabolism of various molecules possessing catechol structure, including catecholamines (such as dopamine, epinephrine, and norepinephrine), estrogens, drugs (e.g., L-DOPA), and xenobiotics including tea catechins and benzo[a]pyrene metabolites (found in tobacco smoke, grilled meats, and other foods). In this process, COMT transfers a methyl group from S-adenosyl methionine (SAM) to a catechol compound, thereby producing S-adenosyl homocysteine (SAH), a homocysteine precursor. This reaction is essential for the detoxification of catechol compounds and the maintenance of appropriate dopamine and norepinephrine levels for optimal brain health (e.g., behavior, cognition, and stress management).

The rs4680 SNP in the COMT gene determines a G to A substitution (forward DNA strand), which in turn produces a substitution from valine (Val) to methionine (Met) at position 158 of the amino acid sequence of the enzyme (Val158Met). This substitution affects COMT's activity, with the variant A (Met) allele producing an enzyme with $40 \%$ lower activity than that encoded by the ancestral $G(V a l)$ allele $[47,48]$. This may result in decreased degradation of neurotransmitters (dopamine, epinephrine, and norepinephrine), estrogen, drugs, and other catechol compounds. As a result, A-allele carriers may have increased sensitivity to environmental toxicants, a higher risk of developing neuropsychiatric disorders, and impaired estrogen metabolism. For example, individuals with genotype AA 
may have a higher risk of developing breast cancer upon exposure to endocrine-disrupting chemicals (EDCs) [49].

The rs4680 SNP may affect the metabolism of certain nutrients and their effects on COMT-mediated detox reactions. Tea catechins such as epigallocatechin-3-gallate (EGCG) are a COMT substrate and may increase COMT activity shortly after consumption when consumed at high doses (500-1000 mg) [50]. Individuals with the AA genotype, who have slow COMT activity, may be slow catechin metabolizers, have a lower catechin excretion in the urine, and retain more catechins in the blood than those with the GG genotype [51,52]. As a result, they may benefit from a lower intake of tea catechins. In contrast, those with the GG genotype, who have higher COMT activity, may be more sensitive to the short-term effects of tea catechins, such as an increase in insulin secretion and blood pressure (BP). These effects were observed in three randomized clinical trials that used high doses of green tea or green tea extract (GTE) consumed before a high carbohydrate meal [53-55].

Individuals with the GG genotype, who have higher COMT activity, may experience the health benefits of olive oil and red wine at lower intakes than those required for individuals with the AA genotype. This is due to a greater ability to convert hydroxytyrosol, a phenolic compound in virgin olive oil and red wine, into its cardioprotective metabolite homovanillyl alcohol (HVAL). In a prospective cohort study in 1851 elderly adults at high risk of cardiovascular disease (CVD), individuals with the GG genotype had significantly higher urinary concentrations of HVAL compared to those with the AA genotype [56].

\subsubsection{Bilirubin Uridine Diphosphate Glucuronosyl Transferase}

Bilirubin uridine diphosphate glucuronosyl transferase (bilirubin-UGT) is a Phase II detoxification enzyme produced by the UGT1A1 gene that conjugates glucuronic acid to a variety of endogenous and exogenous substances such as bilirubin, estrogen, dietary carcinogens, and several medications to facilitate their excretion from the body. This reaction plays an important role in converting toxic unconjugated bilirubin to non-toxic conjugated bilirubin and is involved in the metabolism of $40-70 \%$ of all drugs.

The rs3064744(TA) allele, also known as UGT1A1*28 and previously annotated as rs34815109 or rs34983651, is an insertion variant resulting from the addition of an extra TA nucleotide pair in the promoter region of the UGT1A1 gene. While the -/- and -/TA genotypes do not seem to have any functional or clinical impact, the homozygous (TA/TA) genotype reduces the amount of the bilirubin-UGT enzyme produced by transcription, resulting in a 70\% decrease in enzymatic activity [57]. Consequently, TA/TA individuals may be at higher risk for certain cancers [58] and experience increased toxicity in response to certain drugs such as the chemotherapeutic irinotecan and the antiallergenic drug tranilast [59-61]. Some TA/TA individuals may develop Gilbert syndrome, a benign condition characterized by increased serum levels of total and unconjugated bilirubin and associated with a lower risk of coronary artery disease (CAD). Not all TA/TA individuals develop Gilbert syndrome, indicating the involvement of environmental factors and other genetic variants, such as those in UGT1A6 and UGT1A7 genes, that further regulate the glucuronidation process.

Cruciferous vegetables and apiaceous vegetables may decrease total serum bilirubin levels in rs3064744(TA) allele carriers, with greater effects observed for TA/TA homozygous subjects. In a randomized, controlled, and crossover feeding trial, 70 healthy nonsmoking adults with genotype TA/TA and TA/- experienced, respectively, a $16-21 \%$ and $8 \%$ decrease in bilirubin, a marker of UGT1A1 activity, upon daily consumption of a single or double dose of cruciferous vegetables or a single dose of cruciferous vegetables plus a single dose of apiaceous vegetables for two weeks [42]. Similarly, citrus fruit may help lower serum bilirubin in rs3064744(TA) allele carriers, although these effects may be limited to women with the TA/TA genotype. In an observational study in healthy nonsmoking adults, women with the TA/TA genotype who consumed $\geq 0.5$ daily servings of citrus fruit had $\sim 30 \%$ lower serum bilirubin than those with the same genotype who consumed less, whereas -/and TA/- genotypes did not experience any effects [62]. 


\section{Validation of Genetic Variants of Detox Metabolism in Real-World Clinical Settings}

We next explored the association of the genetic variants presented herein with functional biomarkers of detox metabolism within the Lifestyle Intervention and Functional Evaluation-Health Outcome Survey (LIFEHOUSE), a real-world pragmatic clinical trial (PCT) conducted at the Personalized Lifestyle Medicine Center (PLMC) by Metagenics Inc. The study design and protocol have been described in detail previously [63]. Briefly, LIFEHOUSE utilizes an "N-of-1" and a Tent-Umbrella-Bucket design to define functional markers of health and to model interventions facilitating the adaptation of personalized lifestyle medicine recommendations in an employee health population. For genotyping, version 5 of the 23andMe chip was used.

Gene deletions in GSTM1 and GSTT1 as well as TA insertions in UGTA1 were not included in our analysis as the SNPs used to assess these genetic variants or their surrogates were not available on version 5 of the 23andMe chip. As functional biomarkers of detox metabolism, we evaluated the blood levels of gamma-glutamyltransferase (GGT), homocysteine, and oxidized low-density lipoprotein (oxLDL), as these biomarkers have been identified as reflecting complex interactions between environmental toxicity and physiological disturbances underlying common diseases of aging. Lee and Jacobs have noted that serum GGT levels within its reference range are a sensitive marker of oxidative stress and may provide a valuable marker of exposure to persistent organic pollutants identified as a risk factor for the development of Type 2 Diabetes Mellitus [64,65]. Homocysteine has been demonstrated to be a risk factor for cardiovascular and neurodegenerative disorders with suspected mechanisms including disordered mitochondrial energy production, nitric oxide and peroxynitrate signaling, and oxidative stress [66-68]. Oxidized LDL, reflecting a key precipitating step in endothelial dysfunction and atherosclerosis, may represent a global marker of oxidative stress [69,70].

Tables 3 and 4 show, respectively, the baseline levels of GGT, homocysteine, and oxLDL in the study population and their association with the investigated genetic variants. As shown in Table 4, carrying the effect allele of the genetic variants in CYP1A2 (rs762551C), CYP1B1 (rs1056836-C), or COMT (rs4680-A) correlated with worse detox function or increased oxidative damage, as indicated by higher levels of homocysteine, oxLDL, or GGT. Violins plots in Figure 1 present a visualization of the distribution and statistical summary of the data. Heterozygous subjects tended to have intermediate biomarker levels between those carrying two copies of the effect allele and those carrying two copies of the protective allele. Notably, the alleles linked to lower activity of Phase I enzymes (CYP1A2 rs762551-C, and CYP1B1 rs1056836-G) were associated with greater toxic load in the liver, as indicated by elevated GGT, but lower oxidative damage, as indicated by lower levels of oxLDL and/or homocysteine. In particular, rs762551-C in CYP1A2 was associated with substantially and significantly lower oxLDL. This likely reflects the importance of balancing Phase I and Phase II reactions for effective and safe detoxification as the products of Phase I detox reactions are highly reactive. These metabolites can produce increased oxidative stress unless promptly cleared by Phase II enzymes. Among all associations, only the one between CYP1A2 rs762551 and oxLDL was statistically significant $(p \leq 0.05)$. It is important to note, however, that due to the small sample size, our study was underpowered with respect to detecting potentially clinically significant differences in detox outcomes. Therefore, any statistically significant association or lack thereof must be interpreted with caution. 
Table 3. Baseline demographics and functional biomarkers.

\begin{tabular}{cc}
\hline & Mean (SD) \\
\hline & $n=157$ \\
\hline Age, years & $43(11)$ \\
Sex & $106(68 \%)$ \\
Female & $51(32 \%)$ \\
Male & \\
Ethnicity & $77(49 \%)$ \\
Caucasian & $20(13 \%)$ \\
Asian & $4(2 \%)$ \\
African American & $5(3 \%)$ \\
Mediterranean & $14(9 \%)$ \\
Northern European & $6(4 \%)$ \\
Native American & $19(12 \%)$ \\
Other & $9.1(3)$ \\
Homocysteine $(\mu \mathrm{mol} / \mathrm{L})$ & $3(2 \%)$ \\
Missing & $44(13.8)$ \\
\hline oxLDL (U/L) & $26(16 \%)$ \\
Missing & $22.5(16.7)$ \\
\hline GGT (U/L) & $3(2 \%)$ \\
Missing &
\end{tabular}

Table 4. Association between genetic variants in Phase I/Phase II detox enzymes and levels of homocysteine, oxLDL, and GGT. For each biomarker (rows), we report the mean levels and standard deviation in groups of subjects carrying the same genotype of the selected genetic variants.

\begin{tabular}{|c|c|c|c|c|c|c|c|c|}
\hline & \multicolumn{4}{|c|}{ CYP1A2 I rs762551-C } & \multicolumn{4}{|c|}{ CYP1B1 | rs1056836-C } \\
\hline & Genotype & Subjects (\%) & Mean (SD) & $p$-Value & Genotype & Subjects (\%) & Mean (SD) & $p$-Value \\
\hline \multirow[t]{3}{*}{ Hcy } & AA & $85(55.2)$ & $9.21(2.89)$ & 0.796 & GG & $58(37.7)$ & $8.87(2.34)$ & 0.232 \\
\hline & AC & 57 (37.0) & $8.91(2.90)$ & & CG & 66 (42.9) & $8.77(2.46)$ & \\
\hline & $\mathrm{CC}$ & $12(7.8)$ & $8.71(1.85)$ & & $\mathrm{CC}$ & $30(19.5)$ & $10.05(4.02)$ & \\
\hline \multirow[t]{3}{*}{ oxLDL } & $\mathrm{AA}$ & $66(50.4)$ & $46.21(13.80)$ & 0.018 & GG & 45 (34.4) & 44.82 (11.52) & 0.459 \\
\hline & $\mathrm{AC}$ & $55(42.0)$ & $43.23(13.75)$ & & CG & $58(44.3)$ & $43.01(16.12)$ & \\
\hline & $\mathrm{CC}$ & $10(7.6)$ & $34.00(10.08)$ & & $\mathrm{CC}$ & $28(21.4)$ & 44.85 (12.29) & \\
\hline \multirow[t]{5}{*}{ GGT } & AA & 85 (55.2) & $22.58(17.08)$ & 0.862 & GG & $58(37.7)$ & $22.67(19.29)$ & 0.555 \\
\hline & $\mathrm{AC}$ & $57(37.0)$ & $21.86(15.43)$ & & CG & $66(42.9)$ & $23.77(16.82)$ & \\
\hline & $\mathrm{CC}$ & $12(7.8)$ & $24.33(21.39)$ & & $\mathrm{CC}$ & $30(19.5)$ & $19.1(9.95)$ & \\
\hline & \multicolumn{4}{|c|}{ COMT I rs4680-A } & \multicolumn{4}{|c|}{ Polygenic Risk Score } \\
\hline & Genotype & Subjects (\%) & Mean (SD) & $p$-Value & $\begin{array}{c}\text { Genetic } \\
\text { Risk }\end{array}$ & Subjects (\%) & Mean (SD) & $p$-Value \\
\hline \multirow[t]{3}{*}{ Hcy } & GG & $57(37.0)$ & $9.02(2.49)$ & 0.853 & Low & $88(57.14)$ & $8.79(2.15)$ & 0.215 \\
\hline & AG & $68(44.2)$ & $8.88(2.46)$ & & Medium & $45(29.22)$ & $8.96(2.84)$ & \\
\hline & AA & $29(18.8)$ & $9.54(4.02)$ & & High & $21(13.64)$ & $10.40(4.53)$ & \\
\hline \multirow[t]{3}{*}{ oxLDL } & GG & $48(31.2)$ & $43.08(12.81)$ & 0.728 & Low & $71(54.20)$ & 45.92 (13.32) & 0.103 \\
\hline & AG & 59 (38.3) & 43.85 (14.59) & & Medium & $40(30.53)$ & 40.45 (13.72) & \\
\hline & AA & $24(15.6)$ & $46.38(14.16)$ & & High & $20(15.27)$ & $44.50(15.07)$ & \\
\hline \multirow[t]{3}{*}{ GGT } & GG & $57(37.0)$ & $22.93(19.36)$ & 0.23 & Low & $88(57.14)$ & $24.00(19.25)$ & 0.890 \\
\hline & AG & $68(44.2)$ & $24.44(17.04)$ & & Medium & $45(29.22)$ & 20.16 (12.15) & \\
\hline & AA & $29(18.8)$ & $16.83(6.82)$ & & High & $21(13.64)$ & 20.86 (13.57) & \\
\hline
\end{tabular}

Abbreviations: Hcy: homocysteine; oxLDL: oxidized low-density lipoprotein; GGT: gamma-glutamyltransferase; PRS: Polygenic Risk Score. 

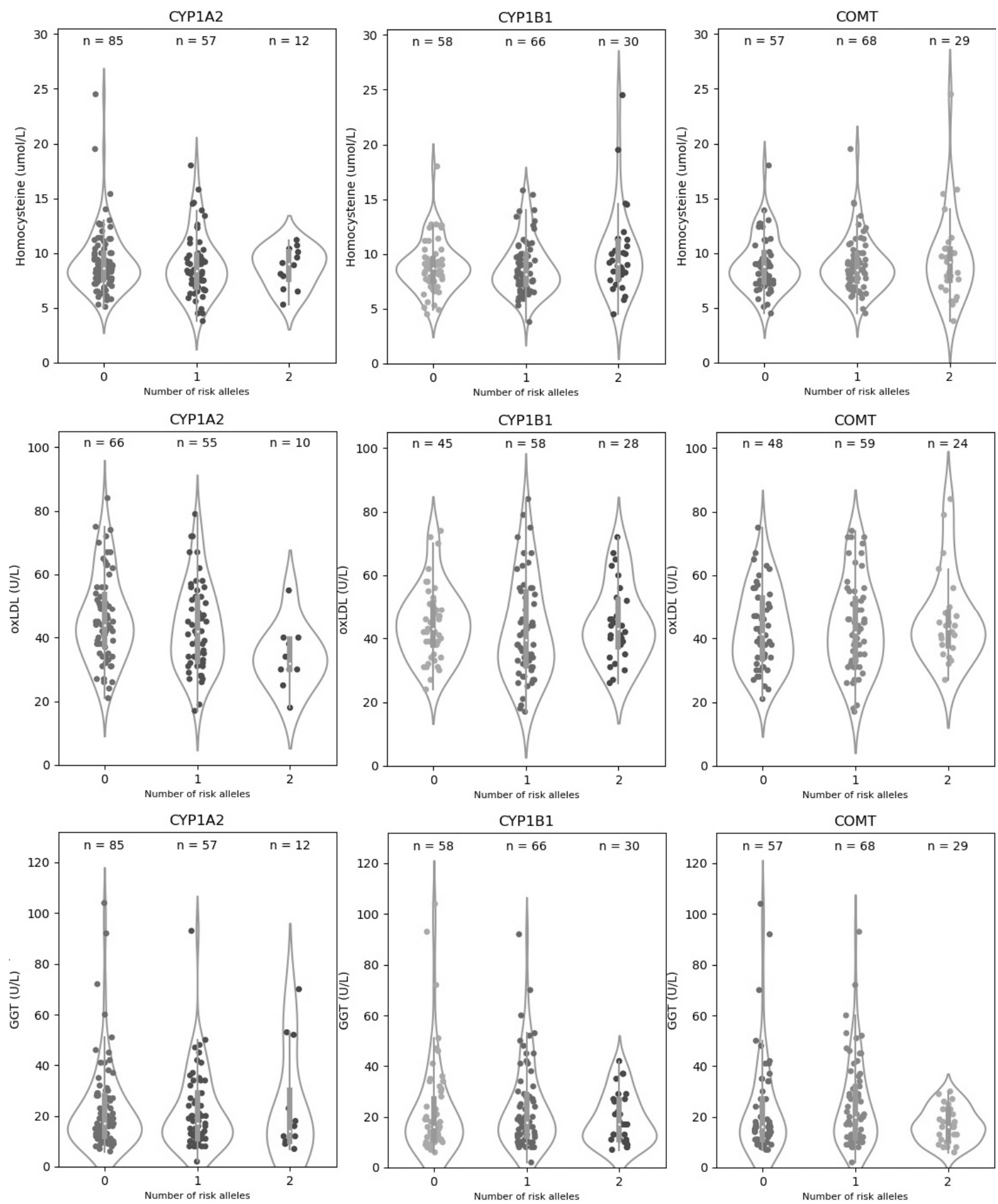

Figure 1. Distribution of homocysteine, oxLDL, and GGT values by genotype. The violin plots show the density plot and statistical summary of homocysteine, oxLDL, and GGT values for each genotype of the CYP1A1, CYP1B2, and COMT genes. The white dot of the box depicts the median, the thick gray bar in the center represents the interquartile range (IQR), which indicates the spread of the middle half of the distribution, and the thin line extending from the gray bar represents the rest of the distribution lying between the $\pm 1.5 \times$ IQR range. The points represent the actual distribution of individual data. On each side of the gray line is a smoothed estimation of probabilities for new points, calculated using the Kernel Density Estimation, showing the distribution shape of the data. Wider sections of the violin plot represent a higher probability that members of the population will have the given value; the skinnier sections represent a lower probability. 
Next, we calculated a polygenic risk score (PRS), including all the above SNPs, to assess their cumulative impact on detox function. In order to calculate PRS, we assigned one point for each effect allele carried by an individual (e.g., zero, one, and two copies) and summed the points for all genetic variants in the score. An equal weight was assigned to each genetic variant. Subjects were ranked by PRS and divided into tertiles corresponding to high, intermediate, or low genetic risk. Genetic risk, as predicted by PRS, did not display a stronger association with homocysteine, oxLDL, or GGT than compared to single SNPs. One of the reasons for this finding is that the "risk allele" as defined in the medical literature does not always correspond to a low-activity protein. This results in discrepant biomarker associations across different variants that, when combined in a PRS, may show worse prediction power than single variants used alone. For example, the risk allele of $C Y P 1 A 2$ is the one that produces a lower activity protein, whereas the risk allele of CYP1B1 produces a high activity protein. Therefore, the risk alleles of $C Y P 1 A 2$ and $C Y P 1 B 1$ show opposite associations with homocysteine, oxLDL, and GGT, and combining these variants into one PRS reduces the power to detect abnormal values in these biomarkers. This suggests that, when dealing with ambivalent risk alleles such as CYP1A2, clinicians may need to use personalized PRSs in which the risk allele is ad hoc chosen based on their patients' individual biomarker imbalances and health goals.

\section{Conclusions}

Thus far, only six variants in genes encoding Phase I and Phase II detox enzymes have been tested in clinical studies: CYP1A2 rs762551; CYP1B1 rs1056836; segmental deletions of GSTT1 and GSTM1; COMT rs4680-A; and insertion variants of UGTA1 (TA/-). None of these variants has been consistently associated with detox-related outcomes in the context of human clinical trials. Therefore, clinicians should always use them in conjunction with functional testing to pinpoint patients that might benefit from specific detox interventions. We identified interesting correlations between SNPs and functional biomarkers of detox function and oxidative stress in our real-world clinical, but still pilot, setting. An important a limitation of this analysis was the lack of information on participants' diet and health status to correlate with genotype and markers of oxidative stress and functional detox. Combining these SNPs in a polygenic risk score (PRS) may enhance their prediction power. However, clinicians must use caution when dealing with genetic variants that can be regarded as risk factors or protective factors depending on an individual's characteristics and health goals. Future studies should validate these variants and their combination in PRSs in large, well-designed clinical studies that investigate the effects of specific interventions on detox-related outcomes and use common standards to define dietary protocols and stratify patients to evaluate heterogeneity of response in different patient subgroups.

Author Contributions: Conceptualization, L.A., J.M.O., J.S.B., B.E., J.J.L., P.M.S. and N.C.; methodology, L.A. and J.M.O.; data analysis and visualization, A.V.; writing-original draft preparation: L.A. and J.M.O.; writing-review and editing: L.A., J.M.O., J.J.L., P.M.S. and N.C.; investigation, J.J.L., P.M.S., D.M. (Deanna Minich), M.L. and M.C.; supervision, L.A., J.M.O. and J.J.L.; project administration, I.A.L. and D.M. (Dina Metti); funding acquisition, B.E. and N.C. All authors have read and agreed to the published version of the manuscript.

Funding: This research was funded by Metagenics, Inc. (Aliso Viejo, CA, USA).

Institutional Review Board Statement: The study was conducted according to the guidelines of the Declaration of Helsinki and approved by the Institutional Review Board of Aspire IRB (protocol code 2018-025PLX, 22 May 2018).

Informed Consent Statement: Informed consent was obtained from all subjects involved in the study.

Data Availability Statement: Data are contained within the article.

Acknowledgments: We thank Brianne Simon, and Kristin Winslow for their contribution to data entry.

Conflicts of Interest: J.J.L. is a co-owner of Personalized Medicine, Inc., which is a consultant for Metagenics, Inc. and a consultant for Nature's Sunshine Products, Inc. (Lehi, UT, USA). P.M.S. is a 
consultant for Metagenics, Inc. (Aliso Viejo, CA, USA). D.M. (Deanna Minich) is an independent contractor for Organic India and Symphony Health, a consultant for Metagenics, Inc., and sits on the Board of Directors for the American Nutrition Association. J.M.O. is a consultant for Metagenics, Inc. B.E. is the president, CEO, and a board-member of Metagenics, Inc.

\section{References}

1. Norman, R.E.; Carpenter, D.O.; Scott, J.; Brune, M.N.; Sly, P.D. Environmental exposures: An underrecognized contribution to non-communicable diseases. Rev. Environ. Health 2013, 28, 59-65. [CrossRef] [PubMed]

2. Moulton, P.V.; Yang, W. Air pollution, oxidative stress, and Alzheimer's disease. J. Environ. Public Health 2012, $2012,472751$. [CrossRef] [PubMed]

3. Grimaldi, K.A.; van Ommen, B.; Ordovas, J.M.; Parnell, L.D.; Mathers, J.C.; Bendik, I.; Brennan, L.; Celis-Morales, C.; Cirillo, E.; Daniel, H.; et al. Proposed guidelines to evaluate scientific validity and evidence for geno-type-based dietary advice. Genes Nutr. 2017, 12, 35. [CrossRef] [PubMed]

4. $\quad$ Eaton, D.L.; Gallagher, E.P.; Bammler, T.K.; Kunze, K.L. Role of cytochrome P4501A2 in chemical carcinogenesis: Implications for human variability in expression and enzyme activity. Pharmacogenetics 1995, 5, 259-274. [CrossRef] [PubMed]

5. Horn, T.L.; Reichert, M.A.; Bliss, R.L.; Malejka-Giganti, D. Modulations of P450 mRNA in liver and mammary gland and P450 ac-tivities and metabolism of estrogen in liver by treatment of rats with indole-3-carbinol. Biochem. Pharmacol. 2002, 64, 393-404. [CrossRef]

6. Nakajima, M.; Yokoi, T.; Mizutani, M.; Kinoshitah, M.; Funayama, M.; Kamataki, T. Genetic Polymorphism in the 5'-Flanking Region of HumanCYP1A2 Gene: Effect on the CYP1A2 Inducibility in Humans. J. Biochem. 1999, 125, 803-808. [CrossRef]

7. Ghotbi, R.; Christensen, M.; Roh, H.-K.; Ingelman-Sundberg, M.; Aklillu, E.; Bertilsson, L. Comparisons of CYP1A2 genetic polymorphisms, enzyme activity and the genotype-phenotype relationship in Swedes and Koreans. Eur. J. Clin. Pharmacol. 2007, 63, 537-546. [CrossRef] [PubMed]

8. Gunes, A.; Ozbey, G.; Vural, E.H.; Uluoglu, C.; Scordo, M.G.; Zengil, H.; Dahl, M.-L. Influence of genetic polymorphisms, smoking, gender and age on CYP1A2 activity in a Turkish population. Pharmacogenomics 2009, 10, 769-778. [CrossRef] [PubMed]

9. Sachse, C.; Brockmöller, J.; Bauer, S.; Roots, I. Functional significance of a C $\rightarrow$ A polymorphism in intron 1 of the cytochrome P450 CYP1A2 gene tested with caffeine. Br. J. Clin. Pharmacol. 1999, 47, 445-449. [CrossRef] [PubMed]

10. Djordjevic, N.; Ghotbi, R.; Jankovic, S.; Aklillu, E. Induction of CYP1A2 by heavy coffee consumption is associated with the CYP1A2-163C $>$ A polymorphism. Eur. J. Clin. Pharmacol. 2010, 66, 697-703. [CrossRef] [PubMed]

11. Wang, L.; Hu, Z.; Deng, X.; Wang, Y.; Zhang, Z.; Cheng, Z.-N. Association between CommonCYP1A2Polymorphisms and Theophylline Metabolism in Non-smoking Healthy Volunteers. Basic Clin. Pharmacol. Toxicol. 2013, 112, 257-263. [CrossRef] [PubMed]

12. Taioli, E.; Garte, S.J.; Trachman, J.; Garbers, S.; Sepkovic, D.W.; Osborne, M.P.; Mehl, S.; Bradlow, H.L. Ethnic Differences in Estrogen Metabolism in Healthy Women. JNCI J. Natl. Cancer Inst. 1996, 88, 617. [CrossRef] [PubMed]

13. Vistisen, K.; Loft, S.; Olsen, J.H.; Vallentin, S.; Ottesen, S.; Hirsch, F.R.; Poulsen, H.E. Low CYP1A2 activity associated with testicular cancer. Carcinogenesis 2004, 25, 923-929. [CrossRef] [PubMed]

14. Danielson, P.Á. The Cytochrome P450 Superfamily: Biochemistry, Evolution and Drug Metabolism in Humans. Curr. Drug Metab. 2002, 3, 561-597. [CrossRef] [PubMed]

15. Božina, N.; Bradamante, V.; Lovrić, M. Genetic Polymorphism of Metabolic Enzymes P450 (CYP) as a Susceptibility Factor for Drug Response, Toxicity, and Cancer Risk. Arch. Ind. Hyg. Toxicol. 2009, 60, 217-242. [CrossRef] [PubMed]

16. Palatini, P.; Ceolotto, G.; Ragazzo, F.; Dorigatti, F.; Saladini, F.; Papparella, I.; Mos, L.; Zanata, G.; Santonastaso, M. CYP1A2 genotype modifies the association between coffee intake and the risk of hypertension. J. Hypertens. 2009, 27, 1594-1601. [CrossRef] [PubMed]

17. Cornelis, M.C.; El-Sohemy, A.; Kabagambe, E.K.; Campos, H. Coffee, CYP1A2 Genotype, and Risk of Myocardial Infarction. JAMA J. Am. Med. Assoc. 2006, 295, 1135-1141. [CrossRef] [PubMed]

18. El-Sohemy, A.; Cornelis, M.C.; Kabagambe, E.K.; Campos, H. Coffee, CYP1A2 genotype and risk of myocardial infarction. Genes Nutr. 2007, 2, 155-156. [CrossRef]

19. Peterson, S.; Schwarz, Y.; Li, S.S.; Li, L.; King, I.B.; Chen, C.; Eaton, D.L.; Potter, J.; Lampe, J.W. CYP1A2, GSTM1, and GSTT1 Polymorphisms and Diet Effects on CYP1A2 Activity in a Crossover Feeding Trial. Cancer Epidemiol. Biomark. Prev. 2009, 18, 3118-3125. [CrossRef] [PubMed]

20. Wilms, L.C.; Boots, A.W.; De Boer, V.C.; Maas, L.M.; Pachen, D.M.; Gottschalk, R.W.; Ketelslegers, H.B.; Godschalk, R.W.; Haenen, G.R.; van Schooten, F.J.; et al. Impact of multiple genetic polymorphisms on effects of a 4-week blueberry juice in-tervention on ex vivo induced lymphocytic DNA damage in human volunteers. Carcinogenesis 2007, 28, 1800-1806. [CrossRef] [PubMed]

21. Li, N.; Mu, Y.; Liu, Z.; Deng, Y.; Guo, Y.; Zhang, X.; Li, X.; Yu, P.; Wang, Y.; Zhu, J. Assessment of interaction between maternal polycyclic aromatic hydrocarbons exposure and genetic polymorphisms on the risk of congenital heart diseases. Sci. Rep. 2018, 8, 3075. [CrossRef] [PubMed]

22. Lampe, J.W.; Chen, C.; Li, S.; Prunty, J.; Grate, M.T.; Meehan, E.D.; Barale, K.V.; Dightman, A.D.; Feng, Z.; Potter, J. Modulation of human glutathione S-transferases by botanically defined vegetable diets. Cancer Epidemiol. Biomark. Prev. 2000, 9, 787-793. 
23. Bailey, L.R.; Roodi, N.; Dupont, W.D.; Parl, F.F. Association of cytochrome P450 1B1 (CYP1B1) polymorphism with steroid receptor status in breast cancer. Cancer Res. 1998, 58, 5038-5041. [PubMed]

24. Paracchini, V.; Raimondi, S.; Gram, I.T.; Kang, D.; Kocabas, N.A.; Kristensen, V.N.; Li, D.; Parl, F.F.; Rylander-Rudqvist, T.; Soucek, P.; et al. Meta- and pooled analyses of the cytochrome P-450 1B1 Val432Leu polymorphism and breast cancer: A HuGE-GSEC review. Am. J. Epidemiol. 2007, 165, 115-125. [CrossRef] [PubMed]

25. Chen, Y.; Xiao, P.; Ou-Yang, D.-S.; Fan, L.; Guo, D.; Wang, Y.-N.; Han, Y.; Tu, J.-H.; Zhou, G.; Huang, Y.-F.; et al. Simultaneous action of the flavonoid quercetin on cytochrome p450 (cyp) 1a2, cyp2a6,n-acetyltransferase and xanthine oxidase activity in healthy volunteers. Clin. Exp. Pharmacol. Physiol. 2009, 36, 828-833. [CrossRef] [PubMed]

26. Moyer, A.M.; Salavaggione, O.E.; Hebbring, S.J.; Moon, I.; Hildebrandt, M.A.; Eckloff, B.W.; Schaid, D.J.; Wieben, E.D.; Weinshilboum, R.M. GlutathioneS-Transferase T1 and M1: Gene Sequence Variation and Functional Genomics. Clin. Cancer Res. 2007, 13, 7207-7216. [CrossRef] [PubMed]

27. Huang, R.S.; Chen, P.; Wisel, S.; Duan, S.; Zhang, W.; Cook, E.H.; Das, S.; Cox, N.J.; Dolan, M.E. Population-specific GSTM1 copy number variation. Hum. Mol. Genet. 2008, 18, 366-372. [CrossRef] [PubMed]

28. Carlsten, C.; Sagoo, G.S.; Frodsham, A.J.; Burke, W.; Higgins, J.P.T. Glutathione S-Transferase M1 (GSTM1) Polymorphisms and Lung Cancer: A Literature-based Systematic HuGE Review and Meta-Analysis. Am. J. Epidemiol. 2008, 167, 759-774. [CrossRef]

29. McDougle, C.J.; Price, L.H.; Goodman, W.K.; Charney, D.S.; Heninger, G.R. A controlled trial of lithium augmentation in fluvoxam-ine-refractory obsessive-compulsive disorder: Lack of efficacy. J. Clin. Psychopharmacol. 1991, 11, 175-184. [CrossRef] [PubMed]

30. Nagle, C.M.; Chenevix-Trench, G.; Spurdle, A.B.; Webb, P.M. The role of glutathione-S-transferase polymorphisms in ovarian cancer survival. Eur. J. Cancer 2007, 43, 283-290. [CrossRef] [PubMed]

31. Ott, K.; Lordick, F.; Becker, K.; Ulm, K.; Siewert, J.; Höfler, H.; Keller, G. Glutathione-S-transferase P1, T1 and M1 genetic polymorphisms in neoadjuvant-treated locally advanced gastric cancer: GSTM1-present genotype is associated with better prognosis in completely resected patients. Int. J. Color. Dis. 2008, 23, 773-782. [CrossRef] [PubMed]

32. Gasper, A.V.; Al-Janobi, A.; Smith, J.A.; Bacon, J.R.; Fortun, P.; Atherton, C.; Taylor, M.; Hawkey, C.J.; Barrett, D.; Mithen, R.F Glutathione S-transferase M1 polymorphism and metabolism of sulforaphane from standard and high-glucosinolate broccoli. Am. J. Clin. Nutr. 2005, 82, 1283-1291. [CrossRef] [PubMed]

33. Steck, S.E.; Gammon, M.D.; Hebert, J.R.; Wall, D.E.; Zeisel, S.H. GSTM1, GSTT1, GSTP1, and GSTA1 polymorphisms and urinary isothiocyanate metabolites following broccoli consumption in humans. J. Nutr. 2007, 137, 904-909. [CrossRef] [PubMed]

34. London, S.J.; Yuan, J.-M.; Chung, F.-L.; Gao, Y.-T.; Coetzee, A.G.; Ross, R.K.; Yu, M.C. Isothiocyanates, glutathione S-transferase M1 and T1 polymorphisms, and lung-cancer risk: A prospective study of men in Shanghai, China. Lancet 2000, 356, 724-729. [CrossRef]

35. Brennan, P.; Hsu, C.C.; Moullan, N.; Szeszenia-Dabrowska, N.; Lissowska, J.; Zaridze, D.; Rudnai, P.; Fabianova, E.; Mates, D.; Bencko, V.; et al. Effect of cruciferous vegetables on lung cancer in patients stratified by genetic status: A mendelian randomisation approach. Lancet 2005, 366, 1558-1560. [CrossRef]

36. Moy, K.A.; Yuan, J.-M.; Chung, F.-L.; Wang, X.-L.; Berg, D.V.D.; Wang, R.; Gao, Y.-T.; Yu, M.C. Isothiocyanates, glutathione S-transferase M1 and T1 polymorphisms and gastric cancer risk: A prospective study of men in Shanghai, China. Int. J. Cancer 2009, 125, 2652-2659. [CrossRef]

37. Gaudet, M.; Olshan, A.; Poole, C.; Weissler, M.; Watson, M.; Bell, D. Diet, GSTM1 and GSTT1 and head and neck cancer. Carcinogenesis 2003, 25, 735-740. [CrossRef]

38. Ambrosone, C.B.; McCann, S.E.; Freudenheim, J.L.; Marshall, J.R.; Zhang, Y.; Shields, P.G. Breast Cancer Risk in Premenopausal Women Is Inversely Associated with Consumption of Broccoli, a Source of Isothiocyanates, but Is Not Modified by GST Genotype. J. Nutr. 2004, 134, 1134-1138. [CrossRef]

39. Joseph, M.A.; Moysich, K.B.; Freudenheim, J.L.; Shields, P.G.; Bowman, E.D.; Zhang, Y.; Marshall, J.R.; Ambrosone, C.B. Cruciferous Vegetables, Genetic Polymorphisms in Glutathione S-Transferases M1 and T1, and Prostate Cancer Risk. Nutr. Cancer 2004, 50, 206-213. [CrossRef]

40. Wang, L.I.; Giovannucci, E.L.; Hunter, D.; Neuberg, D.; Su, L.; Christiani, D.C. Dietary intake of Cruciferous vegetables, Glutathione S-transferase (GST) polymorphisms and lung cancer risk in a Caucasian population. Cancer Causes Control 2004, 15, 977-985. [CrossRef]

41. Navarro, S.L.; Chang, J.L.; Peterson, S.; Chen, C.; King, I.B.; Schwarz, Y.; Li, S.S.; Li, L.; Potter, J.D.; Lampe, J.W. Modulation of human serum glutathione $\mathrm{S}$-transferase A1/2 concentration by cru-ciferous vegetables in a controlled feeding study is influenced by GSTM1 and GSTT1 genotypes. Cancer Epidemiol. Biomark. Prev. 2009, 18, 2974-2978. [CrossRef] [PubMed]

42. Navarro, S.; Peterson, S.; Chen, C.; Makar, K.W.; Schwarz, Y.; King, I.B.; Li, S.S.; Li, L.; Kestin, M.; Lampe, J.W. Cruciferous Vegetable Feeding Alters UGT1A1 Activity: Diet- and Genotype-Dependent Changes in Serum Bilirubin in a Controlled Feeding Trial. Cancer Prev. Res. 2009, 2, 345-352. [CrossRef] [PubMed]

43. Riso, P.; Brusamolino, A.; Moro, M.; Porrini, M. Absorption of bioactive compounds from steamed broccoli and their effect on plasma glutathione S-transferase activity. Int. J. Food Sci. Nutr. 2009, 60, 56-71. [CrossRef]

44. Navarro, S.; Schwarz, Y.; Song, X.; Wang, C.-Y.; Chen, C.; Trudo, S.P.; Kristal, A.R.; Kratz, M.; Eaton, D.L.; Lampe, J.W. Cruciferous Vegetables Have Variable Effects on Biomarkers of Systemic Inflammation in a Randomized Controlled Trial in Healthy Young Adults. J. Nutr. 2014, 144, 1850-1857. [CrossRef] 
45. Yuan, J.-M.; Murphy, S.E.; Stepanov, I.; Wang, R.; Carmella, S.G.; Nelson, H.; Hatsukami, D.; Hecht, S.S. 2-Phenethyl Isothiocyanate, Glutathione S-transferase M1 and T1 Polymorphisms, and Detoxification of Volatile Organic Carcinogens and Toxicants in Tobacco Smoke. Cancer Prev. Res. 2016, 9, 598-606. [CrossRef] [PubMed]

46. Cho, M.-R.; Han, J.-H.; Lee, H.-J.; Park, Y.K.; Kang, M.-H. Purple grape juice supplementation in smokers and antioxidant status according to different types of GST polymorphisms. J. Clin. Biochem. Nutr. 2015, 56, 49-56. [CrossRef]

47. Doyle, A.E.S.; Goodman, J.E.; Silber, P.M.; Yager, J.D. Catechol-O-methyltransferase low activity genotype (COMTLL) is associated with low levels of COMT protein in human hepatocytes. Cancer Lett. 2004, 214, 189-195. [CrossRef] [PubMed]

48. Chen, J.; Lipska, B.K.; Halim, N.; Ma, Q.D.; Matsumoto, M.; Melhem, S.; Kolachana, B.S.; Hyde, T.M.; Herman, M.M.; Apud, J.; et al. Functional Analysis of Genetic Variation in Catechol-O-Methyltransferase (COMT): Effects on mRNA, Protein, and Enzyme Activity in Postmortem Human Brain. Am. J. Hum. Genet. 2004, 75, 807-821. [CrossRef]

49. Ghisari, M.; Long, M.; Røge, D.M.; Olsen, J.; Bonefeld-Jørgensen, E.C. Polymorphism in xenobiotic and estrogen metabolizing genes, exposure to perfluorinated compounds and subsequent breast cancer risk: A nested case-control study in the Danish National Birth Cohort. Environ. Res. 2017, 154, 325-333. [CrossRef]

50. Lorenz, M.; Paul, F.; Moobed, M.; Baumann, G.; Zimmermann, B.F.; Stangl, K.; Stangl, V. The activity of catechol-Omethyltransferase (COMT) is not impaired by high doses of epigallocatechin-3-gallate (EGCG) in vivo. Eur. J. Pharmacol. 2014, 740, 645-651. [CrossRef]

51. Inoue-Choi, M.; Yuan, J.M.; Yang, C.S.; Van Den Berg, D.J.; Lee, M.J.; Gao, Y.T.; Yu, M.C. Genetic Association Between the COMT Genotype and Urinary Levels of Tea Poly-phenols and Their Metabolites among Daily Green Tea Drinkers. Int. J. Mol. Epidemiol. Genet. 2010, 1, 114-123. [PubMed]

52. Brown, A.L.; Lane, J.; Holyoak, C.; Nicol, B.; Mayes, A.E.; Dadd, T. Health effects of green tea catechins in overweight and obese men: A randomised controlled cross-over trial. Br. J. Nutr. 2011, 106, 1880-1889. [CrossRef] [PubMed]

53. Miller, R.J.; Jackson, K.G.; Dadd, T.; Mayes, A.E.; Brown, A.L.; Minihane, A.M. The impact of the catechol-O-methyltransferase genotype on the acute responsiveness of vascular reactivity to a green tea extract. Br. J. Nutr. 2010, 105, 1138-1144. [CrossRef] [PubMed]

54. Miller, R.J.; Jackson, K.G.; Dadd, T.; Mayes, A.E.; Brown, A.L.; Lovegrove, J.A.; Minihane, A.M. The impact of the catechol-Omethyltransferase genotype on vascular function and blood pressure after acute green tea ingestion. Mol. Nutr. Food Res. 2012, 56, 966-975. [CrossRef] [PubMed]

55. Dostal, A.M.; Arikawa, A.; Espejo, L.; Bedell, S.; Kurzer, M.S.; Stendell-Hollis, N.R. Green tea extract and catechol-Omethyltransferase genotype modify the post-prandial serum insulin response in a randomised trial of overweight and obese post-menopausal women. J. Hum. Nutr. Diet. 2016, 30, 166-176. [CrossRef] [PubMed]

56. de la Torre, R.; Corella, D.; Castaner, O.; Martínez-González, M.A.; Salas-Salvador, J.; Vila, J.; Estruch, R.; Sorli, J.V.; Arós, F.; Fiol, M.; et al. Protective effect of homovanillyl alcohol on cardiovascular disease and total mortality: Virgin olive oil, wine, and catechol-methylation. Am. J. Clin. Nutr. 2017, 105, 1297-1304. [CrossRef]

57. Bosma, P.J.; Chowdhury, J.R.; Bakker, C.; Gantla, S.; de Boer, A.; Oostra, B.A.; Lindhout, D.; Tytgat, G.M.J.; Jansen, P.J.M.; Oude Elferink, R.J.; et al. The genetic basis of the reduced expression of bilirubin UDP-glucuronosyltransferase 1 in Gilbert's syndrome. N. Engl. J. Med. 1995, 333, 1171-1175. [CrossRef]

58. Guillemette, C.; Millikan, R.C.; Newman, B.; Housman, E.D. Genetic polymorphisms in uridine diphospho-glucuronosyltransferase 1A1 and association with breast cancer among African Americans. Cancer Res. 2000, 60, 950-956.

59. Danoff, T.M.; Campbell, D.A.; McCarthy, L.C.; Lewis, K.F.; Repasch, M.H.; Saunders, A.M.; Spurr, N.K.; Purvis, I.J.; Roses, A.D.; $\mathrm{Xu}, \mathrm{C}$.-A. Gilbert's syndrome UGT1A1 variant confers susceptibility to tranilast-induced hyperbilirubinemia. Pharm. J. 2004, 4, 49-53. [CrossRef]

60. Perera, M.A.; Innocenti, F.; Ratain, M.J. Pharmacogenetic testing for uridine diphosphate glucuronosyltransferase 1 A1 polymorphisms: Are we there yet? Pharmacotherapy 2008, 28, 755-768. [CrossRef]

61. Palomaki, G.E.; Bradley, L.A.; Douglas, M.P.; Kolor, K.; Dotson, W.D. Can UGT1A1 genotyping reduce morbidity and mortality in patients with metastatic colorectal cancer treated with irinotecan? An evidence-based review. Genet. Med. 2009, 11, 21-34. [CrossRef] [PubMed]

62. Saracino, M.R.; Bigler, J.; Schwarz, Y.; Chang, J.-L.; Li, S.; Li, L.; White, E.; Potter, J.D.; Lampe, J.W. Citrus Fruit Intake Is Associated with Lower Serum Bilirubin Concentration among Women with the UGT1A1*28 Polymorphism. J. Nutr. 2009, 139, 555-560. [CrossRef] [PubMed]

63. Lamb, J.J.; Stone, M.; D'Adamo, C.R.; Volkov, A.; Metti, D.; Aronica, L.; Minich, D.; Leary, M.; Class, M.; Carullo, M.; et al. Personalized Lifestyle Intervention and Functional Evaluation Health Outcomes SurvEy: Presentation of the LIFEHOUSE Study Using N-of-One Tent-Umbrella-Bucket Design. J. Pers. Med. 2022, 12, 115. [CrossRef] [PubMed]

64. Lee, D.-H.; Jacobs, D.R. Is serum gamma-glutamyltransferase a marker of exposure to various environmental pollutants? Free Radic. Res. 2009, 43, 533-537. [CrossRef] [PubMed]

65. Lee, D.H.; Jacobs, D.R., Jr. Serum gamma-glutamyltransferase: New insights about an old enzyme. J. Epidemiol. Community Health 2009, 63, 884-886. [CrossRef] [PubMed]

66. Perna, A.F.; Ingrosso, D.; De Santo, N.G. Homocysteine and oxidative stress. Amino Acids 2003, 25, 409-417. [CrossRef] [PubMed] 
67. Perna, A.F.; Capasso, R.; Acanfora, F.; Satta, E.; Lombardi, G.; Ingrosso, D.; Violetti, E.; Maddalena, M.; De Santo, N.G. Toxic effects of hyperhomocysteinemia in chronic renal failure and in uremia: Cardi-ovascular and metabolic consequences. Semin. Nephrol. 2006, 26, 20-23. [CrossRef] [PubMed]

68. Kaplan, P.; Tatarkova, Z.; Sivonova, M.K.; Racay, P.; Lehotsky, J. Homocysteine and Mitochondria in Cardiovascular and Cere-brovascular Systems. Int. J. Mol. Sci. 2020, 21, 7698. [CrossRef] [PubMed]

69. Richardson, M.L.; Bowron, J.M. The fate of pharmaceutical chemicals in the aquatic environment. J. Pharm. Pharmacol. 2011, 37, 1-12. [CrossRef] [PubMed]

70. Kattoor, A.J.; Pothineni, N.V.K.; Palagiri, D.; Mehta, J.L. Oxidative Stress in Atherosclerosis. Curr. Atheroscler. Rep. 2017, 19, 42. [CrossRef] [PubMed] 